\title{
Research on Chinese and Foreign Cultural Thinking Modes and the Influences on English Education Activities
}

\author{
Lingyun $\mathrm{Yu}$ \\ Sias International University , \\ Xinzheng City, Henan Province ,451150 China
}

\begin{abstract}
In this paper, we conduct research on the Chinese and foreign cultural thinking modes and the basic influences on English education activities. Reading and writing are the input and output of language skills and cultural knowledge. In order to ensure the students in English writing can output tunnel, accurate expression, must first be sure that they have enough English input. As an English teacher, in addition to imparting the skills that students should be encouraged to read a lot about English national culture and customs. While reading, teachers can provide the necessary guidance, to make students consciously comparison between two kinds of culture, and to find out in the express form in English and Chinese languages reflect cultural differences. Only in this way, could the student obtain positive feedback on the education. In the future we will integrate more of the state-of-the-art education modes for systematic optimization of the current perspective.
\end{abstract}

Keywords- English Education, Cultural Thinking, Modes, Chinese and Foreign Countries.

\section{Introduction}

According to the principle of the teaching psychology, migration has positive transfer and negative transfer. In terms of English learning, mother tongue to English, the original English knowledge to new knowledge of English learning to promote role, the positive influence, is called positive transfer that is often said that the migration, it can help students to speed up the understanding and mastering of English. On the contrary, the native language to English, the original English knowledge to new knowledge of
English learning interference or obstruction of the role, a negative impact is called the negative transfer also known as the interference, it will interfere with students' grasp of the English language. Obviously, in English teaching, we should actively use of the positive transfer and avoid negative transfer, so as to improve the quality of English teaching [1-2].

According to the literature review, we summarize the thinking mode differences as the follows. (1) Dialectical thinking and formal logic. Chinese traditional philosophy has always regarded the world as composed of two opposing things the unity of opposites of dialectical thinking of the unity of the nationality is the pursuit of a balanced and symmetrical psychological reasons. English on the basis of logical syntax, past, present, active passive, binary fixed objective is reflected on sentence meaning. (2) Intuition figurative thinking and rational logical thinking. The Chinese mind has a tendency to the concrete performance in the language is as much as possible the use of specific shape, image and the sound to convey ideas and information. Western culture is essentially a kind of rational culture and rationalism is not only the consistent tradition of western culture, but also its important features. (3) Curve and linear thinking. The basic feature of Chinese traditional philosophy thinking is the unity of the subject and object, general is given priority to with people. Western philosophy thinking based on subject and object as the starting point of opposites, the understanding of the formation of a life and the inanimate, known and unknown, material and immaterial, existence and there is no opposition. 
Famous linguist Leonard Bloomfield said clearly: "any foreign language in the meaning of a word or a sentence is always different from the native language of an approximation, corresponding to the words or sentences." Different ethnic groups, often because of the difference of thinking habits and has a different language to communicate on the same objective facts. In the Chinese and English two kinds of, for example, they are all belong to different language families, in the aspect of vocabulary, syntax and rhetoric are of great difference. Nuttal pointed out that the best way to improve foreign language knowledge is life in the midst of a native speaker, and behind this approach is a lot of the reading. In addition, in the teaching, the teacher may through collecting all kinds of syntactic errors in the speaking or writing, and then using the error analysis and find out the difference between mother tongue and target language, let the students master two languages in the syntactic differences, develop students' language ability to recognize and reduce negative transfer of mother tongue. Accordingly, in the figure one, we show the keywords of the contemporary English education.

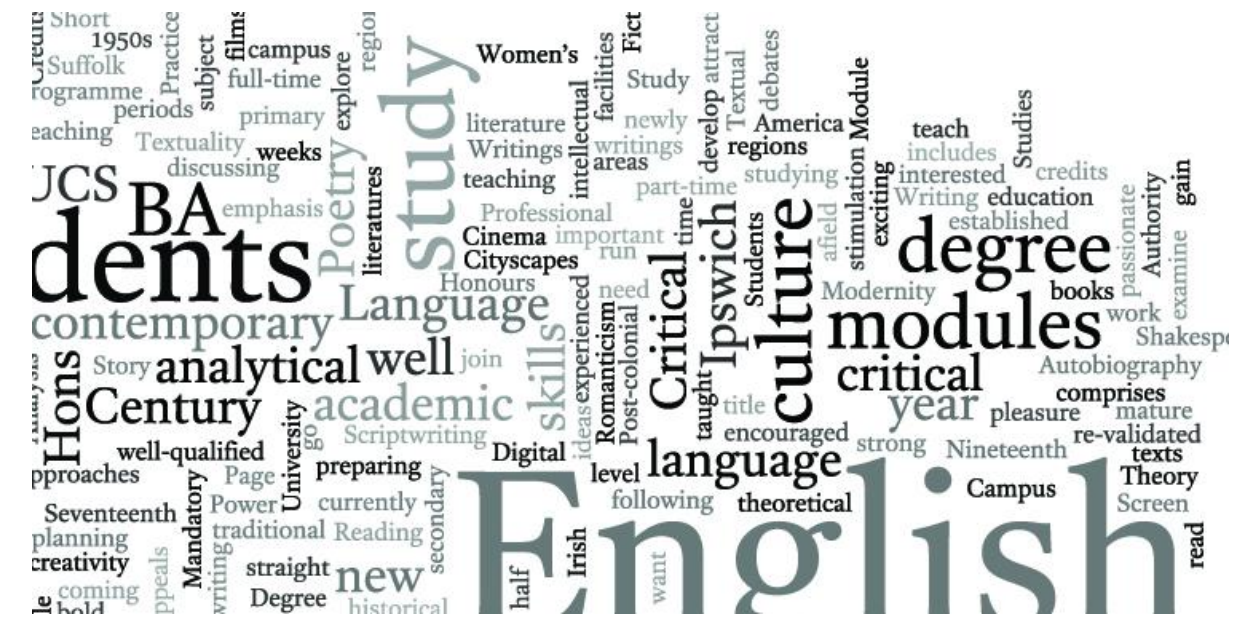

Figure 1. The Keywords of the Contemporary English Education

In this paper, we conduct research on the Chinese and foreign cultural thinking modes and the basic influences on English education activities. As the people on the relationship between language and culture, culture and the communication of understanding and the understanding gradually deepen and thorough, people began to sure the indivisibility between language and culture and the importance of cultural factors in intercultural communication. In the later sections, we will integrate the primary and general features of the Chinese and foreign cultural thinking modes to propose the new perspective on enhancing the contemporary English education performance.

\section{The Proposed Methodology}

The English Education and Culture. It is not enough to only speak English, to say the English has the connotation, so that in the process of communication can having substance in speech, won't make the person produces the feeling that the misunderstanding or words boring hole. Culture is a little different from different countries, especially the huge differences between Chinese and the western culture, which requires students in the learning process to pay attention to and understanding of these different places, so as to fully play the role of language communication [3-4].

The goal of college English teaching is in addition to cultivate students with strong ability 
of basic reading and listen to, say, writing, translation ability, so that they can exchange information in the English, we should also help students to improve the comprehensive cultural quality, in order to meet the need of social development and basic economic construction. So in the language teaching, culture teaching is very important. Humans are able to decompose naturally, will naturally form concept and meaning, mainly because every society agree according to a certain kind of thinking mode to organize natural phenomenon, this kind of thinking mode is also known as cultural thinking mode, it applies to the speech community, embodied in the language of the society. In the process of the communication, people according to their own mode of thinking, language, expression of intention to pass by, and in understanding discourse and who have similar thinking.

College English teaching is not only a language teaching, but also should include cultural teaching. We cannot turn a blind eye to the cultural differences, otherwise, the effect on language teaching and cultural disconnect and make our students lack of cross-cultural awareness. In traditional teaching, we used to think that even in the real language environment, as long as the content repetition, the rote learning, also can practice makes perfect, freely to language communication. Now, with popularity of communicative language teaching, we recognize that we need to put learners in use of real language environment of the target language communication, repetitions, just may get no obstacle, no pause of the thinking and the expression that could be achieve by following the listed suggestions. (1) Cultural contrast teaching. Using correlation method to teaching English is an important means of intercultural language teaching. Chinese on the own cultural nature is quite familiar with, for the western culture is unfamiliar. (2) Supplementary method after class. Now class English learning cannot meet the needs of students learning, teachers can ask students use of after-school time for learning, which can help students understand the cultural background of the English using relevant knowledge, and avoid the student to grow tired of too much homework. (3) Lexical substitution method. Words in English are basically has many meanings, especially under the different scenarios may be the same words have different meanings that cannot treat as the same [5].

The Chinese and Foreign Cultural Thinking Modes. Due to the historical, political, geography, religion, factors such as different, lead to the culture of different countries and regions, this is called cultural differences. Cultural differences would be embodies in each aspect, we should be aware of the differences between Chinese and western culture is not to be ignored and change we should accept the difference, and the differences, respect and understanding. In cross-cultural communication and processing in the process of practical problems, avoid the cultural conflicts, so as to the successful cross-cultural communication smoothly.

\section{Thinking Strategies}

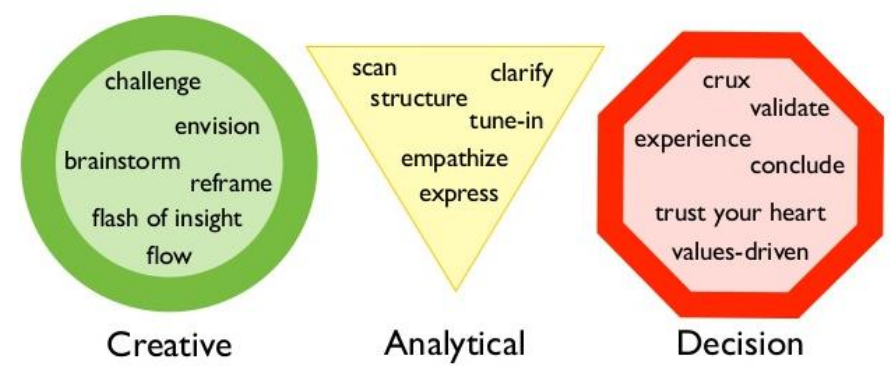

Figure 2. The Thinking Modes and Related Thinking Strategies

On cultural personality, the general oriental values advocate groups, while the westerners advocate individual value; The Oriental pay attention to social ethics, westerners pay attention to individual moral; Oriental introverted, emotion connotation, while the westerners outgoing, outspoken; Oriental look at things image, comprehensive way of thinking, 
westerners in abstract, analysis the thinking way of looking at things. These differences are reflected in the language, the translation should pay the special attention to, lest cause communication error [6].

- Cultural connotation differences of the vocabulary. All kinds of thing on the different national psychology of the meaning of the symbol, it contains the moral of also is not the same. There are many color words in English and Chinese languages have different cultural meanings.

- The differences of address forms. Every language, after long time of development and evolution, will form their own unique call system and the use of standard. Not only that but different address forms use on different occasions, using in different relationships also marked the different emotional color [7].

- Introduces the differences between. In the general process of interpersonal communication, introduction to introduce own and others is essential to social activities and communicative manners, is many strangers to meet or make important bridge. Meaning is relatively accurate that maintain the function of communication is important. From relatives call system, China's relatives call system is more complex and has a wealth of words.

The Migration of Culture in English Teaching. Different national cultural differences between the peoples will cause the difference of values and the different customs and habits, and inevitably reflected in the language features and language use. Negative transfer of culture has a variety of the different level, in terms of foreign language learning and basic communication, to have vocabulary, pragmatics and discourse level, etc. Psychological linguists Anderson believed that language learning is a process, including the understanding process and the generation process.
Understand the process and has three components: perception process, construction process and use process. Gass on second language acquisition from the perspective of cognition to pick the "migration" first language as an important strategy in the process of language acquisition and some Odlin understanding of migration seems to be more objective. He thought the "migration" refers to the language and from have mutual influence between the target language. This effect may be positive, and also may be side effects.

In the process of English teaching, teachers can adopt comparative analysis, for some errors by the comparing language to the correct them. For the large difference of Chinese-English two languages, teachers can guide students to give more attention, more efforts to explain, through more practice and consolidate the use, enable students to master the correct usage. To broaden the way of language input and channels, after class, students are encouraged to use a variety of media way to learn English, lets the student in a lot of contact, in the process of practice, the use of English, experience in the language in English and Chinese languages and cultural differences. From this definition we can induce the information of cultural attribute, culture is not innate, but it has the permeability, concealment, once mastered, it is hard to get rid of it; Culture is a collection of crowd behavior rules, this has resulted in huge differences between different cultures; Culture involves all levels such as material, social system and concept, not only that, at all levels are connected to each other, and interact with each other.

The English Education Optimization. Intercultural communication is based on the basis of the rational understanding of different cultures the rational understanding of different culture depends on whether we have broad cultural vision. Have broad cultural vision means that we can fully accept the different culture paradigm and establish the global coordinates, with the 
same reference in the cultural cross-references in wide area, diverse culture field of vision [8].

Cross-cultural English teaching requires a teacher should have the culture of abstraction and the reduction ability, this includes: from the representational abstracts the cultural norms and the law of the life, understand the cultural implications behind the thinking habits and the behavior; Restore a simple cultural norms to vivid life context, emotional and ability to migrate. The construction of the college English formative assessment system need to schools, teachers, parents and students of all parties to cooperate and the first of all the parties to a unified evaluation concept, from the traditional dominated by summative evaluation, on the basis of score evaluation, pure concept of the managers evaluate the evaluators. The institutions of higher learning should make full use of multimedia and network technology, the new teaching model to improve the original mainly teachers teach a single classroom teaching mode. New modern teaching model should be to modern information technology, especially network technology as the support, make the English teaching is not limited by time and the place, development in the direction of individualized learning and autonomous learning.

How to improve the students' social culture in college English teaching ability, training for the future of intercultural awareness and ability of the college students is a teacher of English had to the problem of serious thinking, therefore, we have a responsibility to our college English teaching in the reflection of culture. In college English cross-cultural teaching, the teacher must first have a correct cross-cultural attitude: equal dialogue cultural attitude of relativism. This requires the teacher must discard cultural centralism and admitted that the rationality of the existence of cultural differences, in an objective, tolerant attitude towards intercultural communication and dialogue.

\section{Conclusion}

In this paper, we conduct research on Chinese and foreign cultural thinking modes and influences on English education activities. Language form both in English and Chinese have the different unique characteristics, is the result of the differences of the Chinese and western way of thinking. Thinking mode is the direct result of cultural differences, cultural differences and lead to negative transfer of the culture. It can be thought of thinking lead to cultural differences cultural differences lead to negative transfer of culture and the thinking mode in the cultural negative transfer plays a decisive role. Under this circumstance, we propose the novel perspective on the English education activities that is novel and beneficial for enhancing the further development pattern.

\section{References}

[1] Fredericks, Bronwyn, et al. "Living with the Legacy of Conquest and Culture: Social Justice Leadership in Education and the Indigenous Peoples of Australia and America." International Handbook of Educational Leadership and Social (In) Justice. Springer Netherlands, 2014. 751-780.

[2] Mullen, Carol A., et al. "An epistemic frame analysis of neoliberal culture and politics in the US, UK, and the UAE." Interchange 43.3 (2013): 187-228.

[3] Wilkinson, D. A. R. R. E. L. L. "Educational Reforms and Development in Japan: Language and Culture Education for Global Competitiveness." International Journal of Higher Education Management (IJHEM) Vol 1.2 (2015): 1-11.

[4] Kesler, Ted, Pablo PL Tinio, and Brian T. Nolan. "What's Our Position? A Critical Media Literacy Study of Popular Culture Websites With Eighth-Grade Special 
Education Students." Reading \& Writing Quarterly 32.1 (2016): 1-26.

[5] Capraro, Robert M., et al. "Through biodiversity and multiplicative principles Turkish students transform the culture of STEM education." International Journal of Education in Mathematics, Science and Technology 4.1 (2016): 1-8.

[6] Ma, Lei. "Problems Discussion and Strategy Research on Cross-culture Foreign Language Teaching over National Universities." 3rd International Conference on Science and Social Research (ICSSR 2014). Atlantis Press, 2014.

[7] Kepa, Mere, et al. "E kore e ngaro nga kakano i ruia mai i Rangiatea: The language and culture from Rangiatea will never be lost in health and ageing research." AlterNative: An International Journal of Indigenous Peoples 10.3 (2014): 276.

[8] Kirkpatrick, Andy. English as an international language in Asia: Implications for language education. Springer Netherlands, 2012. 